Proceeding Paper

\title{
An Investigation of Digital Technology Implementation in Off-Site Construction with a Focus on Efficiency Improvement ${ }^{\dagger}$
}

\author{
Mudan Wang (D), Cynthia Changxin Wang *(D), Samad Sepasgozar (D) and Sisi Zlatanova (D) \\ School of Built Environment, The University of New South Wales, Sydney, NSW 2052, Australia; \\ mudan.wang@student.unsw.edu.au (M.W.); sepas@unsw.edu.au (S.S.); s.zlatanova@unsw.edu.au (S.Z.) \\ * Correspondence: cynthia.wang@unsw.edu.au \\ † Presented at the 3rd Built Environment Research Forum, Sydney, Australia, 1 December 2021
}

check for updates

Citation: Wang, M.; Wang, C.C.; Sepasgozar, S.; Zlatanova, S. An Investigation of Digital Technology Implementation in Off-Site

Construction with a Focus on Efficiency Improvement. Environ. Sci. Proc. 2021, 12, 8. https://doi.org/ 10.3390/environsciproc2021012008

Academic Editor: Khan Rahmat Ullah

Published: 18 February 2022

Publisher's Note: MDPI stays neutral with regard to jurisdictional claims in published maps and institutional affiliations.

Copyright: (C) 2022 by the authors. Licensee MDPI, Basel, Switzerland. This article is an open access article distributed under the terms and conditions of the Creative Commons Attribution (CC BY) license (https:// creativecommons.org/licenses/by/ $4.0 /)$

\begin{abstract}
Digital technologies are supposed to be used to obtain higher efficiency and quality in offsite construction. This research is an on-going thesis project and aims to identify the challenges and expectations of digital technologies' implementation in off-site construction, and also aims to develop a practical application for promoting one of the promising digital technologies. Mixed research methods are conducted in Chinese off-site construction projects, including a set of semi-structured interviews, observation and site experimentation. The major challenges and expectations of digital technology implementation are presented. Specifically, laser scanning technology is expected to be used to check the installation quality of prefabricated wall panels, and it has been validated as practical and efficient in a case study. Further research will be more focused on validating the robustness of using the laser scanning approach.
\end{abstract}

Keywords: digital construction; off-site construction; technology implementation

\section{Introduction}

Off-site construction (OSC) has generally been regarded as a more productive and sustainable construction method [1]. However, this construction method still has many challenges to be resolved regarding installation time, skill requirements and the cost of new tasks related to production and installation [2]. For example, some scholars reported that the total time from design to onsite assembly could be longer or need a higher level of construction details compared to conventional construction methods [3]. On the other hand, digital technologies have been identified that could improve the quality of OSC projects as well as reduce cost and save time and labor, such as building information modelling (BIM) [4,5], radio frequency identification devices (RFID) [6], and laser scanning [7,8]. Previous studies have also investigated digital technology implementation for OSC. However, there is a lack of first-hand investigation from the construction industry regarding digital technology implementation in OSC, and how those technologies can currently be used to improve the efficiency of OSC.

Therefore, this study explores the current challenges of selected examples of OSC that use relevant digital technologies. This study aims to present a set of issues arising from the examples, along with potential technical solutions, and develop a practical application for promoting one of the promising digital technologies. This study also discusses the challenges of digital technology adoption and the expectation of selected practitioners.

\section{Methodology}

Mixed qualitative and quantitative methods are used to address the research questions. Figure 1 shows that semi-structured interviews, observation and site experiments are used for developing a framework of digital technology implementation (DTI) for OSC. The first step is to make industry investigation in OSC industry. The DTI for OSC is assessed, and 
it also identifies one promising technology for OSC. Second, based on the step 1, laser scanner is selected for improving efficiency in the quality-check process. Algorithms are developed and experimentations are conducted for validation. This paper presents the initial outcome of interviews and experiments. Qualitative interview data are analyzed, based on thematic analysis, to identify a set of key factors and patterns of DTI. Laserscanned data are processed by designed codes in the Python environment, including algorithms of segmentation and classification, and procedures which allow quality checks of horizontal alignment and verticality.

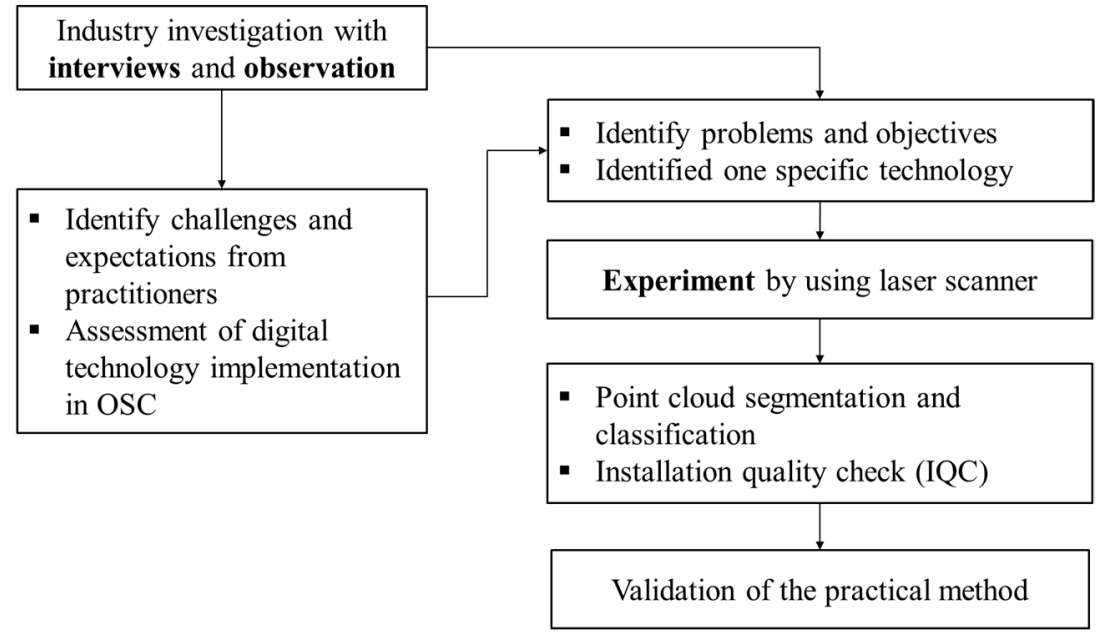

Figure 1. The research flowchart including different key steps of investigations, such as interviews, site-visits, and generating point-cloud using laser scanner.

\section{Results}

\subsection{Findings of the Industry Investigation}

The investigation consists of interviews with 22 practitioners and observation of six OSC projects in China. Based on thematic analysis in NVivo, 12 digital technologies have been identified from the interview as well as their capability in solving construction problems, including BIM, laser scanning, photogrammetry, virtual reality/augmented reality (VR/AR), big data, RFID, robotics, the Internet of Things (IoT), GPS, 3D printing, and artificial intelligence (AI). BIM is the most mentioned technology, with 68 quotes $(38.20 \%)$, especially in the design stage. The second and third mentioned technologies are photogrammetry, with 28 quotes (15.73\%), and laser scanning, with 27 quotes $(15.17 \%)$, both in the manufacture and onsite construction stages, where VR/AR with 12 quotes $(6.74 \%)$ and RFID with 11 quotes $(6.18 \%)$ are also mentioned. Some technologies, including big data, IoT, robot, 3D printing and $\mathrm{AI}$, are less frequently mentioned.

Based on the thematic analysis on interviews and observations, it can be concluded that there are high demands for digital technologies in the OSC industry. Real-time information exchange and delivery of the whole process, automated design, construction monitoring, and higher accuracy checking techniques are the major expectations from the professions. In addition, specific professions presented different needs for digital technologies. Designers are more concerned about the usage of BIM for automated design and Design For Manufacture and Assembly (DfMA) purposes, while manufacturers expect to utilize automation, digitalization and informatization in the factory by integrating BIM with RFID, robotics, VR/AR, photogrammetry, and laser scanning tools. On the other hand, construction contractors are more interested in real-time monitoring using photogrammetry, laser scanning, and VR/AR, to ensure quality and efficiency of the assembly process.

The challenges for digital technology implementation in OSC are caused by people's negative attitude toward adopting new technologies, lack of standardization in OSC, inefficient organizational structure and poor management of technology implementation. 
Lack of standardization of prefabricated elements also plays a significant role in digital technology implementation because if there are too many types of prefabricated elements, a higher level of digital technology needs to be developed to accommodate them, leading to lower efficiency and higher cost. Moreover, government and organizational strategies for using digital technologies in OSC should be established according to the identified challenges.

Therefore, based on the investigation, a more efficient quality check measurement will be developed for prefabricated wall panel installation to replace manual operation, as seen in Figure 2. Laser scanning is considered as a promising technology that can be used to improve efficiency in quality checking [9].
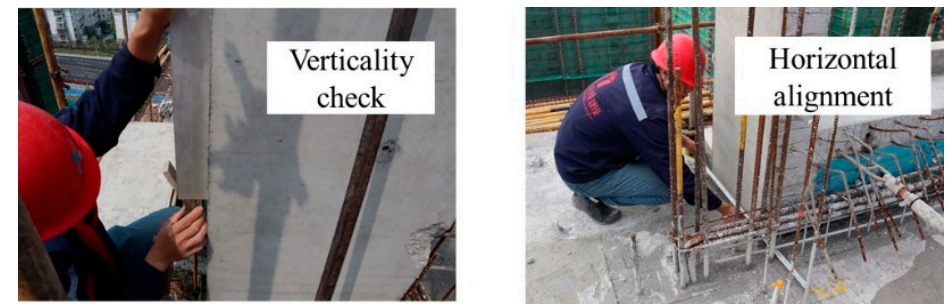

Figure 2. Installation and manual quality check procedures of prefabricated wall panels (PWPs) on OSC.

\subsection{Findings of Using Laser Scanning}

Laser scanning is used to provide an efficient installation quality check (IQC). The goal is to identify the PWPs that need rectification. In the data processing of a laser-scanned point cloud, the points of PWPs are identified based on segmentation and plane fitting algorithms. The process of determining the segmentation parameters for the point cloud data, collected by the BLK 360 laser scan is seen in Figure 3. Figure 3a shows the collected point cloud data after being co-registration in Leica Cyclone software. The segmentation results of the point cloud data are shown in Figure 3b. This process included the experiments to find suitable segmentation using a region growing algorithm, which is a commonly used segmentation method, and provided suggested values for the segmentation parameters. Plane fitting is used to estimate the geometrical parameters of the best plane for the individual segments, and will be used to compute the installation quality of each PWP, as seen in Figure 3c. Finally, Figure 3d shows the PWPs needing rectification are identified based on the proposed IQC method. Suggested values for segmentation are provided, which have rarely been explored in previous studies. This method will be extended to other laser scanners in a further study.

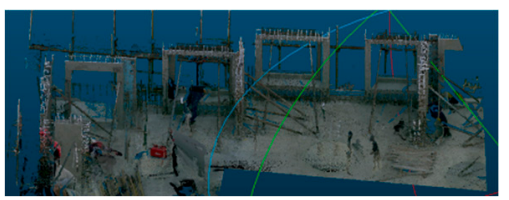

(a)

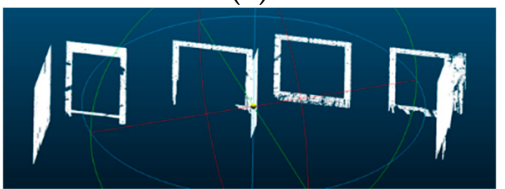

(c)

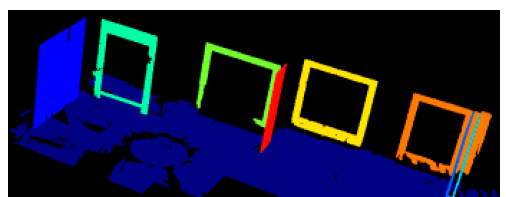

(b)

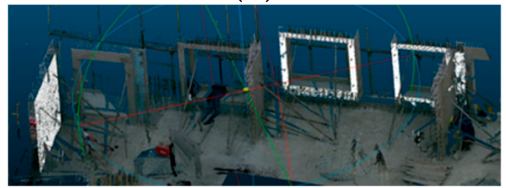

(d)

Figure 3. Point cloud data processing identifying PWPs requiring rectification. (a) Collected point cloud data; (b) Point cloud segmentation; (c) Plane fitting of PWPs; (d) PWPs requiring rectification (shown in white outline). 


\section{Conclusions}

The initial results of this on-going project show the major expectations and challenges surrounding DTI in the current OSC industry, and the validation of the proposed IQC method using laser scanning. Based on the interviews and observation, laser scanning is the preferred method for use in installation quality checks of PWPs. From the case study experiments, the installation quality check can be conducted in a much shorter time frame using the proposed laser scanning method. For example, the checking time using the current manual method was $2-3 \mathrm{~h}$ for one floor. The proposed method can complete scanning, transfer the data for analysis, and produce the outcome, all in less than $1 \mathrm{~h}$ for the same floor. If a larger floor area and more PWPs are to be checked, the advantage of time saving could be significant. The suggested values of segmentation parameters can be used in similar projects.

Expected future steps of this project are: (1) to validate the proposed IQC method using more data collected by different laser scanners; (2) to validate the method in more case study scenarios and improve it as a robust method. Ultimately, this study could provide some practical guidance to government and construction organizations on how to facilitate the development and effective utilization of digital technologies in OSC.

Author Contributions: Conceptualization, M.W., C.C.W., S.S. and S.Z.; methodology, M.W., C.C.W., S.S. and S.Z.; software, M.W.; validation, C.C.W., S.S. and S.Z.; formal analysis, C.C.W., S.S. and S.Z.; investigation, M.W.; resources, C.C.W., S.S. and S.Z.; data curation, M.W.; writing-original draft preparation, M.W.; writing-review and editing, C.C.W., S.S. and S.Z.; visualization, M.W.; supervision, C.C.W., S.S. and S.Z.; project administration, C.C.W.; funding acquisition, C.C.W., S.S. and S.Z. All authors have read and agreed to the published version of the manuscript.

Funding: This research was funded by the University of New South Wales (UNSW Sydney) Scientia PhD Scholarship Scheme.

Institutional Review Board Statement: Not applicable.

Informed Consent Statement: Not applicable.

Data Availability Statement: The data presented in this study are available on request from the corresponding author.

Conflicts of Interest: The authors declare no conflict of interest.

\section{References}

1. Wang, M.; Wang, C.C.; Sepasgozar, S.; Zlatanova, S. A Systematic Review of Digital Technology Adoption in Off-Site Construction: Current Status and Future Direction towards Industry 4.0. Buildings 2020, 10, 204. [CrossRef]

2. Li, C.Z.; Hong, J.; Xue, F.; Shen, G.Q.; Xu, X.; Mok, M.K. Schedule risks in prefabrication housing production in Hong Kong: A social network analysis. J. Clean Prod. 2016, 134, 482-494. [CrossRef]

3. Liu, H.; Singh, G.; Lu, M.; Bouferguene, A.; Al-Hussein, M. BIM-based automated design and planning for boarding of light-frame residential buildings. Autom. Constr. 2018, 89, 235-249. [CrossRef]

4. Yin, X.; Liu, H.; Chen, Y.; Al-Hussein, M. Building information modelling for off-site construction: Review and future directions. Autom. Constr. 2019, 101, 72-91. [CrossRef]

5. Sepasgozar, S.M.E.; Costin, A.; Wang, C. Challenges of Migrating from Desktop-based BIM in Construction. In Proceedings of the 33rd International Symposium on Automation and Robotics in Construction (ISARC 2016), Auburn, AL, USA, 18-21 July 2016; pp. 934-942.

6. Luo, L.; Jin, X.; Shen, G.Q.P.; Wang, Y.; Liang, X.; Li, X.; Li, C.Z. Supply Chain Management for Prefabricated Building Projects in Hong Kong. J. Manag. Eng. 2020, 36, 05020001. [CrossRef]

7. Sepasgozar, S.; Wang, C.; Shirowzhan, S. Challenges and Opportunities for Implementation of Laser Scanners in Building Construction. In Proceedings of the 33rd International Symposium on Automation and Robotics in Construction (ISARC 2016), Auburn, AL, USA, 18-21 July 2016; pp. 742-751.

8. Sepasgozaar, S.M.E.; Shirowzhan, S.; Wang, C. A Scanner Technology Acceptance Model for Construction Projects. Procedia Eng. 2017, 180, 1237-1246. [CrossRef]

9. Wang, M.; Wang, C.C.; Zlatanova, S.; Sepasgozar, S.; Aleksandrov, M. Onsite Quality Check for Installation of Prefabricated Wall Panels Using Laser Scanning. Buildings 2021, 11, 412. [CrossRef] 